\title{
Incidence and Mortality Trends of Acute Gastroenteritis and Pneumococcal Disease in Children Following Universal Rotavirus and Pneumococcal Conjugate Vaccination in Ecuador
}

\author{
Patricia Juliao (D) - Adriana Guzman-Holst (D) • Vinay Gupta • \\ Claudia Velez $\cdot$ Tamara Rosales $\cdot$ Carlos Torres
}

Received: June 30, 2021 / Accepted: August 16, 2021 / Published online: September 21, 2021

(C) The Author(s) 2021

\begin{abstract}
Introduction: Ecuador introduced routine infant rotavirus (RV) vaccination in 2008 and pneumococcal conjugate vaccination (PCV) in 2011 to manage disease and mortality in children caused by gastroenteritis (GE) and by pneumonia (PNE) and invasive pneumococcal disease (IPD), respectively.

Methods: This retrospective ecological database study described vaccination coverage as well as the trends in incidence and mortality in the preversus post-vaccination periods and used timetrend analysis models to assess the impact of vaccination.

Results: RV vaccination coverage of the second dose was between 79-97\% from 2008 to 2016 . GE incidence and mortality showed a declining
\end{abstract}

Supplementary Information The online version contains supplementary material available at https:// doi.org/10.1007/s40121-021-00531-6.

P. Juliao · A. Guzman-Holst ( $₫)$

GSK, Ciudad del Saber Edificio 230, Panama City, Panama

e-mail: adriana.x.guzman@gsk.com

V. Gupta · C. Velez

JSS Research, Saint Laurent, QC, Canada

T. Rosales

GSK, Quito, Ecuador

C. Torres

Admirhserv, Quito, Ecuador trend before vaccination which continued in the post-vaccination period. The model estimated a statistically significant decrease of $72.4 \%$ for GE mortality and $51.2 \%$ for GE incidence in the post-vaccination period. PCV vaccination coverage remained above $80 \%$ (second dose) and 40\% (third dose) after 2011. PNE mortality showed a declining trend before vaccination and a continued decline after vaccination, while PNE incidence was more variable (sharp increase from 2005-2009 then decrease and eventual stabilisation). The model estimated a statistically significant decline of $41.1 \%$ for PNE mortality and a stable PNE incidence in the post- versus pre-vaccination period. IPD incidence and mortality yearly data showed large variability by year and low numbers, making it difficult to discern a trend. The model estimated a statistically significant reduction of $51.1 \%$ for IPD mortality and $31.5 \%$ for IPD incidence in the post- versus pre-vaccination period.

Conclusion: After the first 9 years of routine RV vaccination and 6 years of routine PCV vaccination in Ecuador, significant decreases in incidence and mortality in children $<5$ years of age due to GE and pneumococcal disease have been observed. 


\section{Graphical Abstract:}

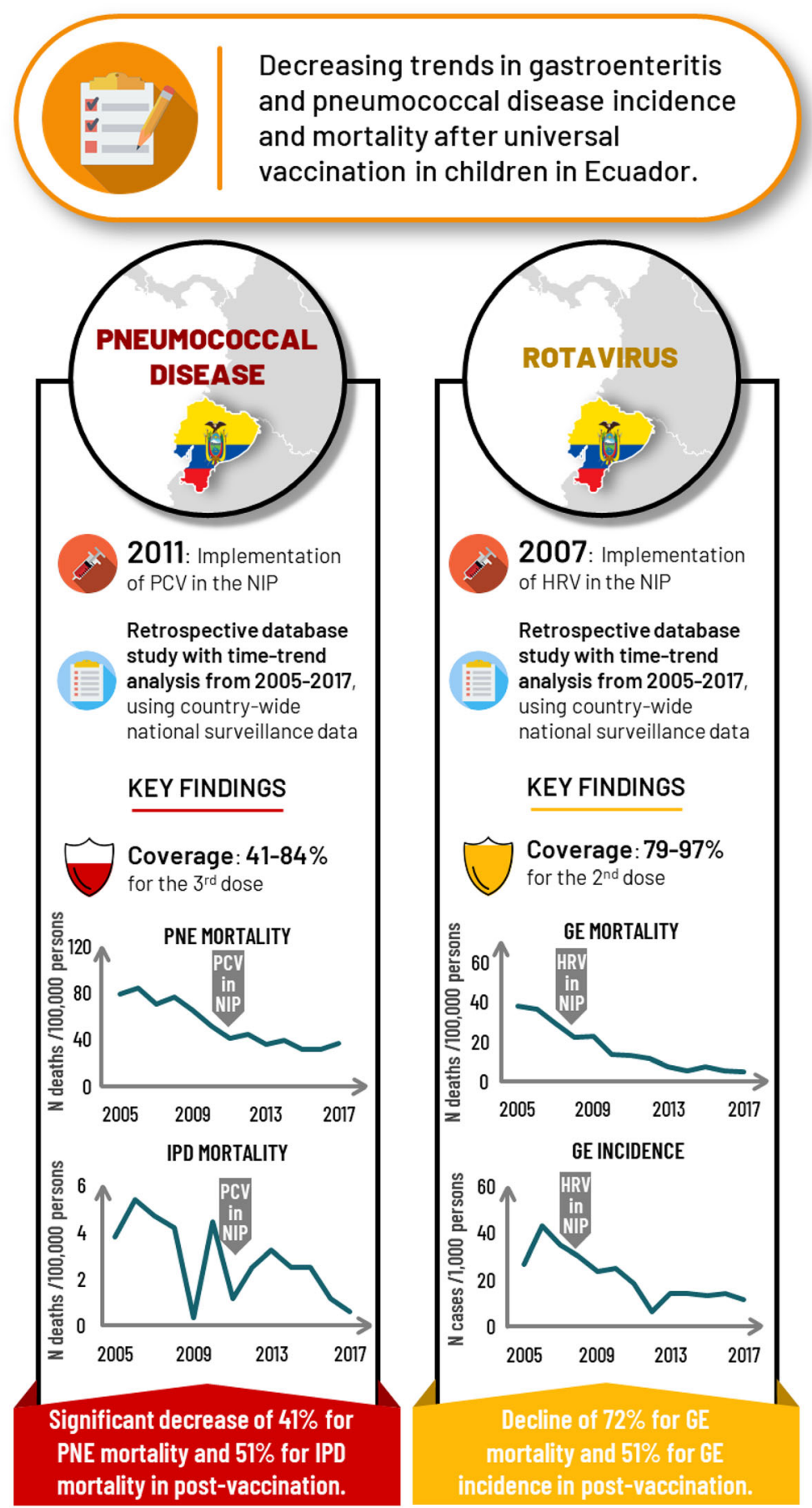

GE: gastroenteritis; HRV: Human-attenuated rotavirus vaccine; IPD: invasive pneumococcal disease; NIP: National Immunization Program; PCV: pneumococcal conjugate vaccine; PNE: pneumonia; RV: rotavirus. This infographic represents the opinions of the authors. For a full list of declarations, including funding and author disclosure statements, please see the full text online. (c) The authors, CC-BY-NC 2021.

\begin{tabular}{|c|c|c|c|}
\hline $\begin{array}{l}7.0 P E N \\
2 \text { ACCESS }\end{array}$ & $\begin{array}{l}\text { PEER-REVIEWED } \\
\text { INFOGRAPHIC }\end{array}$ & \multirow{2}{*}{$\begin{array}{l}\text { Ecuador: Incidence and mortality trends of acute } \\
\text { gastroenteritis and pneumococcal disease in children following } \\
\text { universal rotavirus and pneumococcal conjugate vaccination. } \\
\text { Juliao P, Guzman-Holst A, Gupta V, Velez C, Rosales T, Torres C. }\end{array}$} & \multirow{2}{*}{ 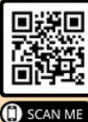 } \\
\hline A & Adis & & \\
\hline
\end{tabular}


Keywords: Diarrhea; Ecuador; Incidence; Infant mortality; Invasive pneumococcal disease; Pneumonia; Rotavirus; Vaccination

\section{Key Summary Points}

Why carry out this study?

This study described the incidence and mortality of gastroenteritis (GE) following the first 9 years of universal rotavirus vaccination, and of pneumonia (PNE) and invasive pneumococcal disease (IPD) following the first 6 years of universal pneumococcal conjugate vaccination in Ecuador

A time-trend analysis model estimated the impact of vaccination

What was learned from the study?

GE mortality and incidence started to decline before vaccination, and the model estimated a significant decrease in the post- compared with the pre-vaccination period

PNE mortality started to decline before vaccination, and the model estimated a significant decrease post-vaccination, while PNE incidence remained stable

IPD mortality and incidence varied year by year before vaccination, post-vaccination; the model estimated a significant decline in both

\section{DIGITAL FEATURES}

This article is published with digital features, including a graphical abstract, to facilitate understanding of the article. To view digital features for this article go to https://doi.org/10. 6084/m9.figshare. 15172752 .

\section{INTRODUCTION}

Rotavirus (RV) infection is the leading cause of severe diarrhea, which is still a main cause of mortality worldwide in children $<5$ years of age $[1,2]$. Before vaccination, nearly $40 \%$ of childhood diarrheal deaths were due to RV, primarily in developing countries [3, 4]. In Latin America, RV accounted for $24 \%$ of gastroenteritis (GE) cases overall (31\% in Ecuador) and nearly $30 \%$ of hospitalized GE cases $(33 \%$ in Ecuador) between 1977 and 2009. During this time, the annual GE mortality rate was 88.2 (93 in Ecuador) per 100,000 children $<5$ years of age [5]. In 2005, in Ecuador, GE was the first cause of hospitalization in children (i.e., $11 \%$ of all hospitalizations) and the seventh cause of infant mortality (0.6/1000 births) [6].

$\mathrm{RV}$ is a common pathogen for which vaccination is the most effective public health strategy. Two effective RV vaccines with an acceptable safety profile are currently licensed in infants: Rotarix (GSK, Belgium) [7, 8], a twodose human attenuated vaccine (HRV), and RotaTeq (MSD, USA), a three-dose bovine-human reassortant vaccine (BHRV) $[9,10]$. Both vaccines protect against major circulating $\mathrm{RV}$ serotypes.

As the fourth Millennium Development Goal is to reduce childhood mortality by two-thirds, the World Health Organization (WHO) recommends infant RV vaccination worldwide $[11,12]$. Several Latin American countries have successfully implemented it since 2006 [11], and Ecuador introduced HRV in the National Immunization Program (NIP) at the end of 2007 [13] with $80 \%$ coverage in 2016 [14]. The proportion of diarrhea due to RV post-vaccination was estimated to have declined by $37 \%$ in 2012 (from 30 to $18.8 \%$ ) [15] and by $46 \%$ (in 2011-2013) in a study in rural Ecuador [16].

Streptococcus pneumoniae infections are leading causes of community-acquired pneumonia and invasive pneumococcal disease (IPD, e.g., meningitis and sepsis) in children $<5$ years of age, as well as less severe otitis media [17]. In 2000, there were over 14.5 million severe cases and an estimated 826,000 child deaths worldwide due to pneumococcal diseases, 


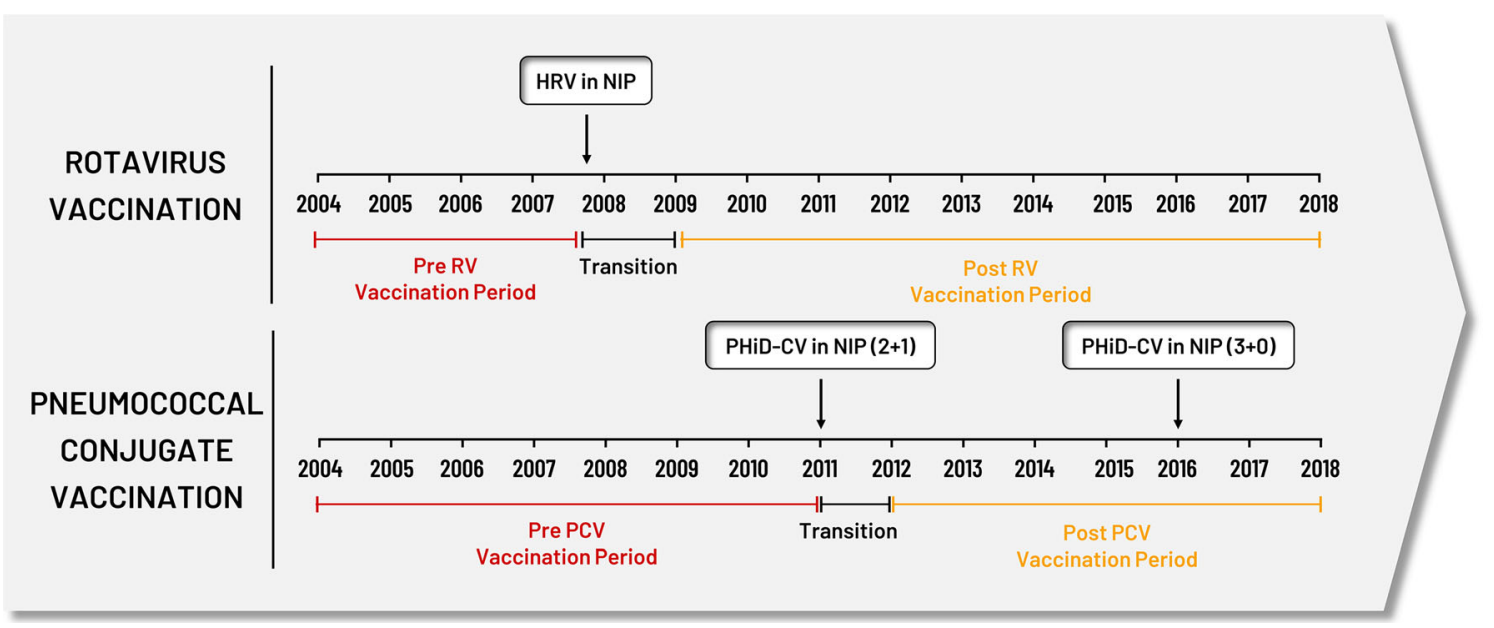

Fig. 1 Pre-vaccination, transition and post-vaccination periods studied for RV and PCV. Figure shows the prevaccination study periods, the transition periods when universal rotavirus (RV) and pneumococcal conjugate vaccination $(\mathrm{PCV})$ were introduced into the NIP (National Immunization Program) in Ecuador and the post-

representing around $11 \%$ of all deaths in this age group [17]. In 2009, annual estimates for the Latin America and Caribbean region predicted 18,000 deaths [18], over 1.4 million outpatient visits and 182,000 hospitalizations due to pneumococcal disease in children $<5$ years of age $[19,20]$. With its high morbidity and mortality, pneumococcal disease is considered an important vaccine-preventable cause of death in children [21]. Routine pneumococcal conjugate vaccine (PCV) immunization is the most effective public health strategy to prevent pneumococcal disease [21].

There are $>90$ known $S$. pneumoniae serotypes, of which 8-11 cause most cases of severe pneumococcal disease [22]. The first PCV (PCV7, licensed in 2000) provided protection against seven serotypes and was later replaced by two effective vaccines with good safety profiles comprising more serotypes: PHiD-CV (pneumococcal polysaccharide non-typeable Hemophilus influenzae protein D-conjugate vaccine, Synflorix, GSK in 2009) [23] comprising ten serotypes, and PCV13 (diphtheria CRM protein conjugate vaccine Prevenar, Wyeth/Pfizer in 2010) [24] comprising 13 serotypes [25]. vaccination study periods. Rotarix (HRV) was administered against RV in a two-dose schedule given at 2 and 4 months. The PCV was PHiD-CV, used in a $2+1$ schedule (at 2 and 4 months with a booster dose at 12-15 months) from 2011 to 2015 and then a $3+0$ schedule (at 2, 4 and 6 months of age) from 2016 onwards

In 2012, the WHO recommended PCVs worldwide, especially in high-mortality countries [26], and in 2019, the recommendation was broadened to all countries regardless of mortality [22]. Countries in Latin America were among the first developing countries to introduce universal PCV programs, with 34 countries offering routine PCV by 2015 [20, 27]. Ecuador first introduced PCV vaccination in 2008 for high-risk groups and then recommended the universal infant PCV (PHiD-CV) vaccination in 2010 (implemented in the NIP in 2011 [13]), achieving coverage of $>90 \%$ from 2012 to 2015 [28].

The objectives of this study were to: (1) describe trends in incidence and mortality of GE and pneumococcal disease in children $<5$ years of age in Ecuador between 2005 and 2017, as well as vaccine coverage, from pre- to postvaccine periods and (2) use time-trend analysis to assess the impact of vaccination after adjusting for other variables. The results of this study will help policymakers evaluate the impact of immunization programs on public health. 


\section{METHODS}

\section{Study Design and Population}

A retrospective ecological database study was conducted to assess GE and pneumococcal disease incidence and mortality trends in children, before and after the introduction of HRV (October 2007) and PHiD-CV (February 2011) vaccination in Ecuador. A pre- and postvaccination period were defined as well as a transition period for the year of vaccine introduction (Fig. 1). Vaccine coverage was also assessed over the study period.

Outcomes were assessed in all children $<5$ years of age and in children $<2$ years of age where disease burden is highest and based on the availability and national stratification of the data. Outcomes were evaluated at the national level as well as in four regions, as follows: Sierra (Carchi, Imbabura, Pichincha (includes capital city, Quito), Cotopaxi, Tungurahua, Bolívar, Chimborazo, Cañar, Azuay, Loja, Santo Domingo de los Tsáchilas), Oriente (Sucumbíos, Napo, Pastaza, Orellana, Morona Santiago, Zamora Chinchipe), Costa (Esmeraldas, Manabí, Guayas, Los Ríos, El Oro, Santa Elena) and Insular (Galápagos).

The main databases from INEC (Instituto Nacional de Estadísticas y Censos [National Census and Statistics Bureau]) was searched for population projections and for GE, pneumonia (PNE) and IPD cases and deaths (using ICD-10/ ICD-9 codes), captured by the public surveillance system. The database from Dirección General de Salud [Department of Health] was

\section{ROTAVIRUS \\ NATIONAL VACCINATION COVERAGE}
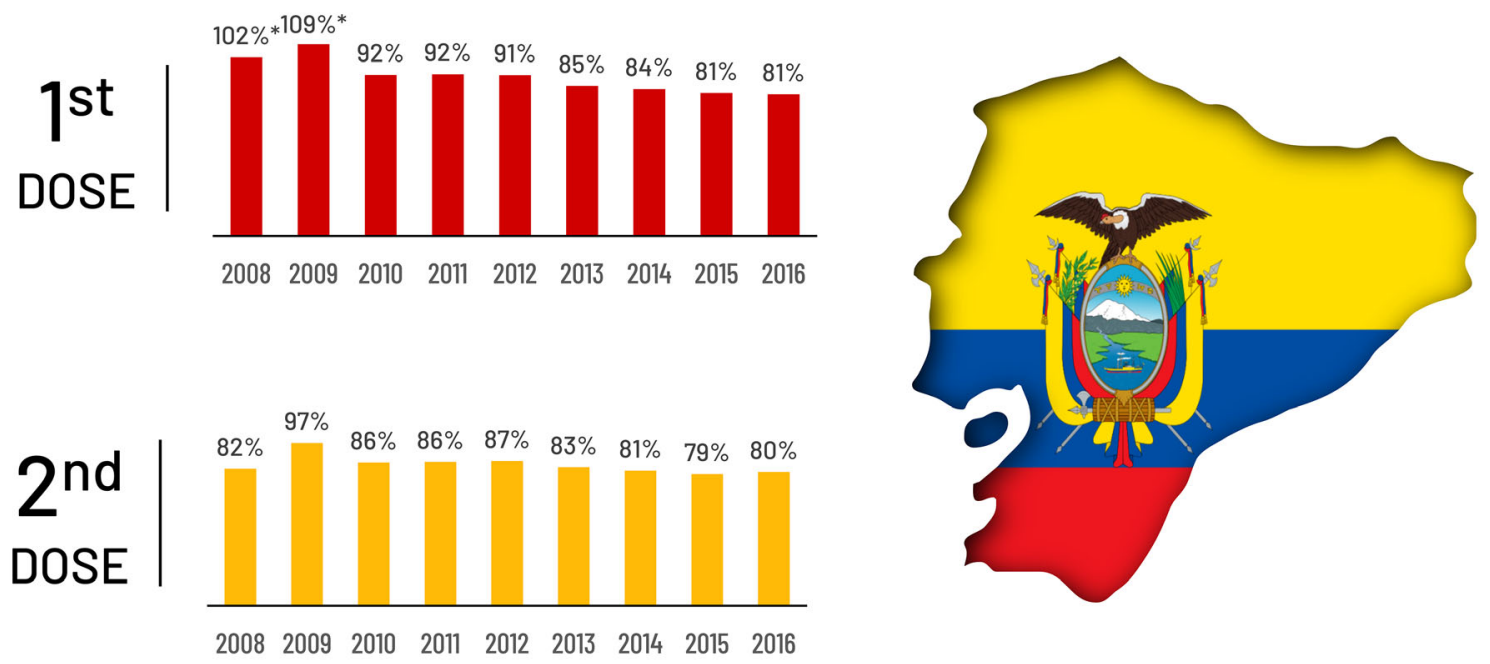

$20082009201020112012 \quad 20132014 \quad 20152016$

After the introduction of Rotavirus vaccination in the NIP at the end of 2007, vaccination coverage of the $2^{\text {nd }}$ dose ranged from $79-97 \%$ at a National level.

Fig. 2 RV vaccine coverage data. No data were available by region or the year 2017. The population of infants $<1$ year old was used as the denominator. NIP National Immunization Program. ${ }^{*}$ Coverage levels $>$ $100 \%$ are occasionally reported in national administrative databases as a result of systematic error in the numerator or denominator, such as the inclusion of children outside the target age group in the numerator 


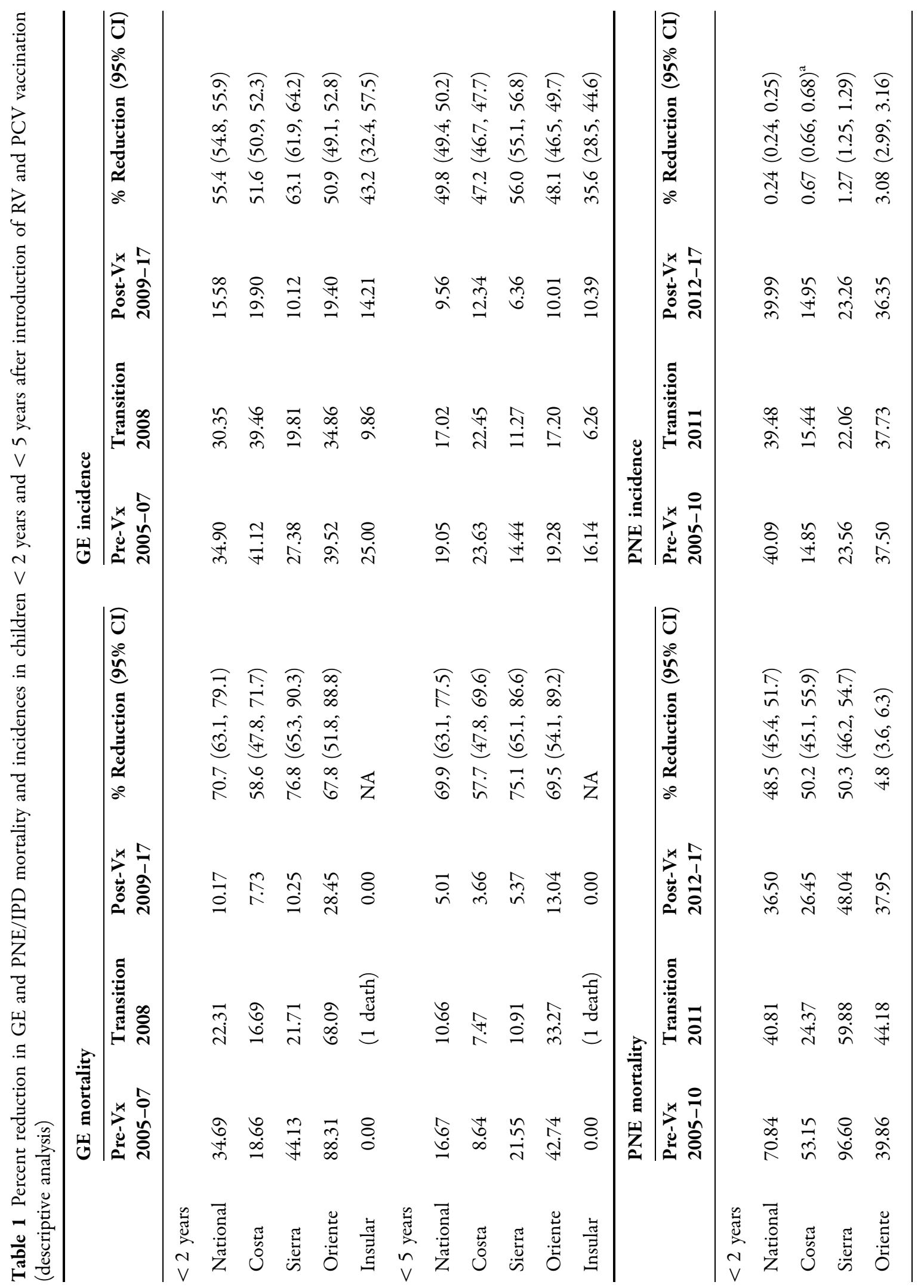




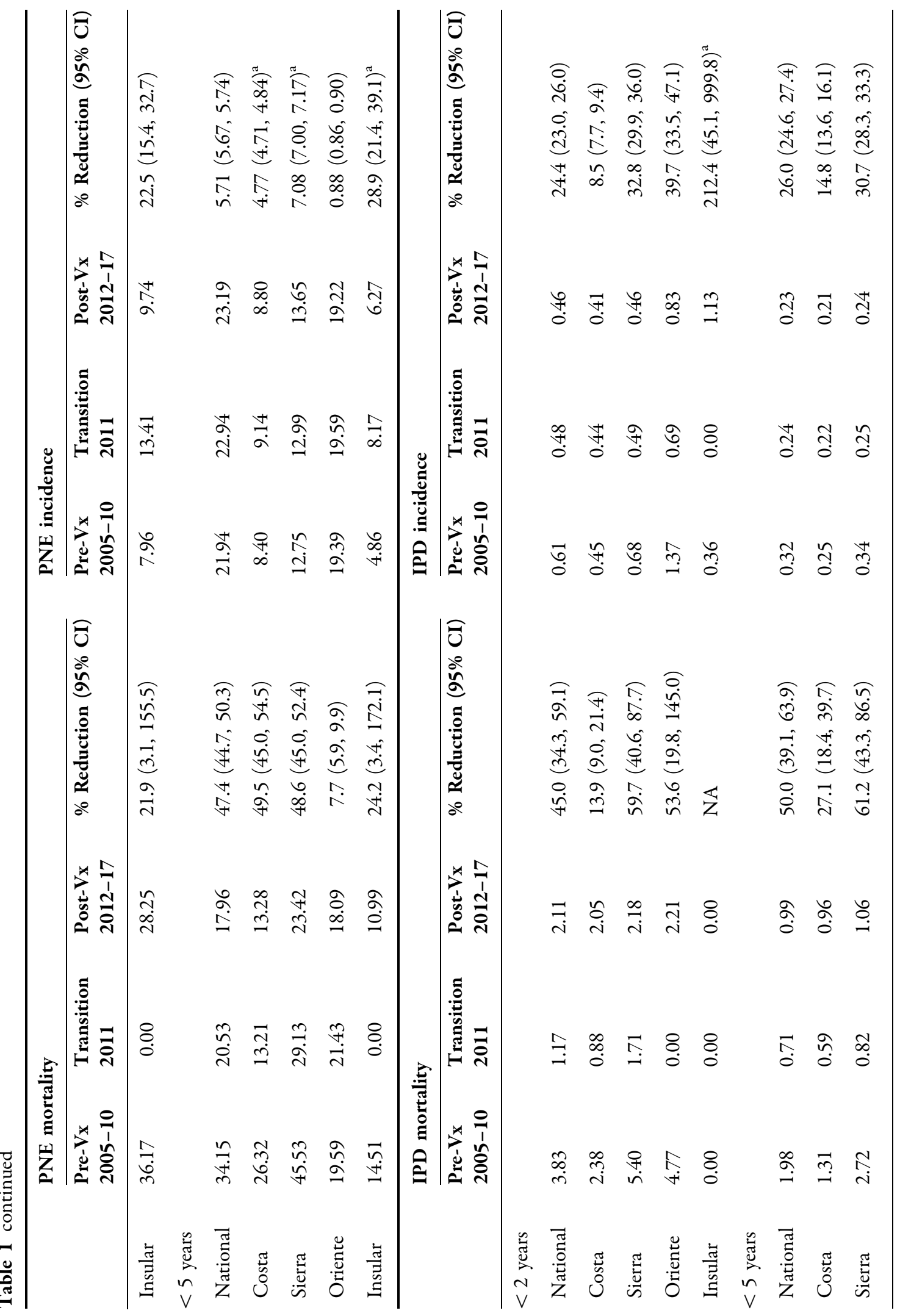




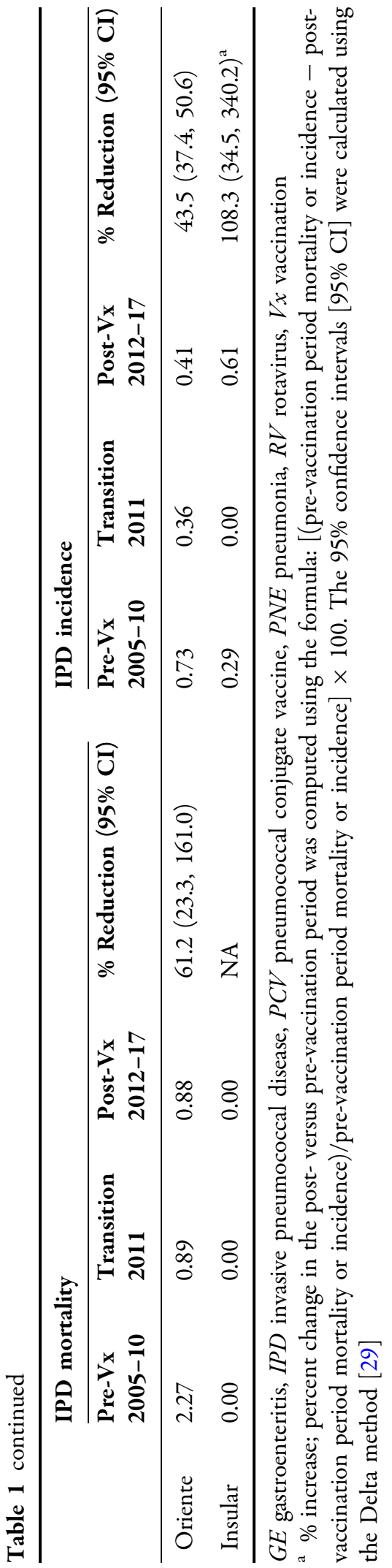

searched for vaccine coverage data (Supplementary table 1 ).

\section{Descriptive Analysis and Time-Trend Analysis}

For the descriptive analysis, outcome data were tabulated by month and year, age group, region, and vaccination period. Mortality was calculated as: number of deaths in a year (and/or month)/total population) $\times 100,000$. Incidence was calculated as: number of cases in a year (and/or month)/total population) $\times 1000$. The total population (denominator) refers to the total national population of children $<5$ years. Population projections for children aged 0-2 years were not available. As such, yearly population estimates for this age group were estimated by adding the $0-1$-year-old population of the previous year into the current population of 0 -1-year-olds.

The percent change in the post- versus prevaccination period was computed using the formula: [(pre-vaccination period mortality or incidence - post-vaccination period mortality or incidence)/pre-vaccination period mortality or incidence] $\times 100$. The $95 \%$ confidence intervals $[95 \% \mathrm{CI}]$ were calculated using the Delta method [29].

Vaccine coverage data were summarized per calendar year since NIP introduction, using frequency and percentage, with population projections for the correct age group per dose used as the denominator to calculate the percentage.

For the time-trend analysis, the percent change in incidence and mortality post-vaccination with 95\% CI was explored using several generalized linear regression models. The Poisson model was the best fit for the data [using log (Number of cases or deaths) $=\log$ (population projections + intercept $+\beta 1$ Year or Month)] Vaccination period was a dummy/indicator variable, with 0 denoting the pre-vaccination period, 1 denoting the transition period and 2 denoting the post-vaccination period. The model included year/month for the effects of secular trends and could include other relevant covariates (e.g., age group and region), if found 


\section{(a) GE MORTALITY}
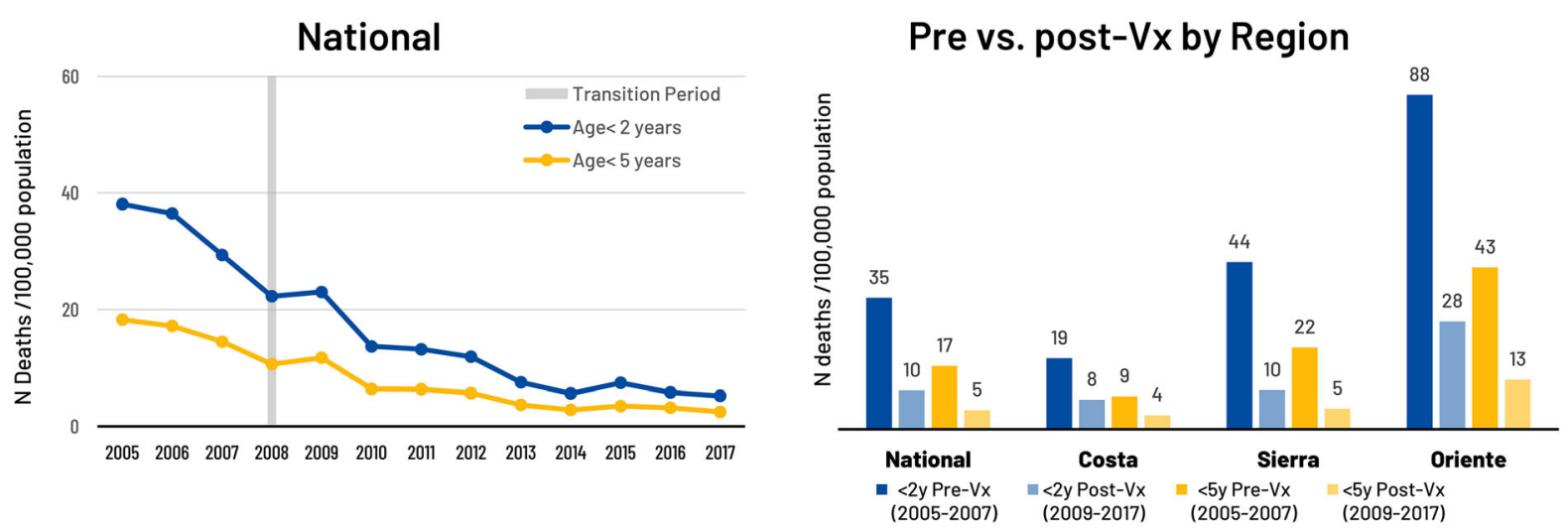

(b) GE INCIDENCE

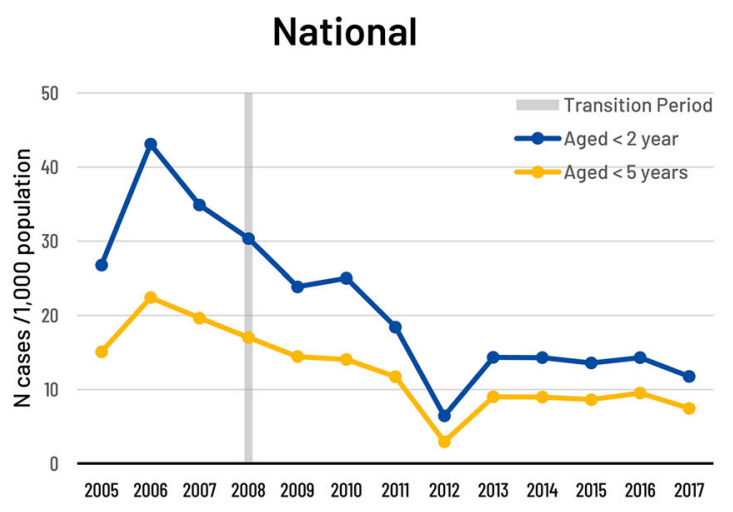

Fig. 3 National GE a mortality $(/ 100,000)$ and $\mathbf{b}$ incidence $(/ 1000)$ yearly trends (descriptive analysis). $G E$ gastroenteritis, $N$ number, $V x$ vaccination, $y$ years.

to be significantly associated with the outcome in initial univariate analyses and if they did not add an interaction effect.

All descriptive and time-trend analyses were conducted in SAS v9.4 and R 3.6.3.

\section{Compliance with Ethics Guidelines}

This study used anonymized aggregated database data with no personally identifiable information which can be linked to a patient. It was therefore considered out of scope for ethics review based on Ministerial Agreement MSP-
Pre vs. post-Vx by Region

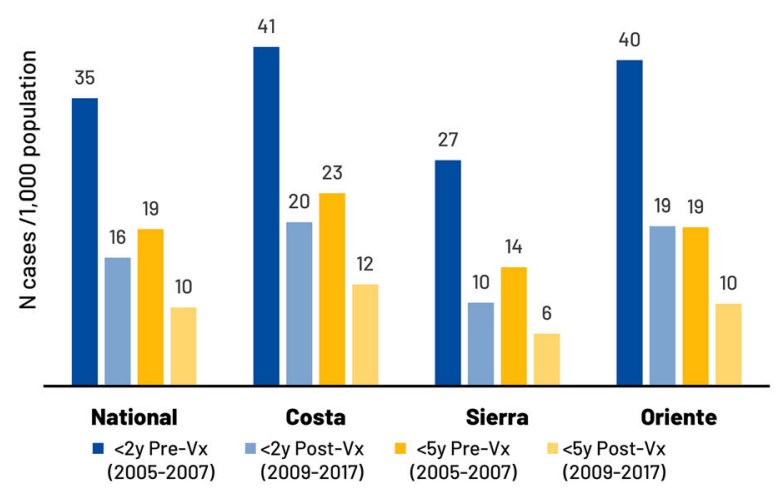

Transition period: period during which the rotavirus vaccination was introduced in Ecuador. ICD-10 codes used were Intestinal Infectious Disease A00-A09

CGDES-2018-0185-O from Ecuador's Ministry of Health (Coordinación General de Desarrollo Estratégico en Salud).

\section{RESULTS}

\section{RV Vaccination and Impact on GE Mortality and Incidence}

\section{$R V$ Vaccine Coverage}

After universal RV vaccination was introduced at the end of 2007, national vaccine coverage of 
the last (2nd) dose ranged between 79 and 97\% (Fig. 2). No data were available by region or for the year 2017 and after.

\section{GE Mortality}

In 2005-2017, there were 1329 GE deaths in children $<2$ years $(1622$ in children under 5 years). The highest number of deaths was in the Sierra region (647), followed by Costa (433) and Oriente (238), with just one death in the Insular region (during the transition period). Prior to vaccination, GE mortality was 34.69/ 100,000 nationwide, with the highest rate in Oriente (88.31) and the lowest in Costa (18.66) region. Following RV vaccination, GE mortality significantly declined by $70.7 \%$ [63.1, 79.1] nationwide and in all regions by $58.6-78.6 \%$ (Table 1, Supplementary Fig. 1a). Among all children $<5$ years, GE mortality was lower (i.e., $16.7 / 100,000$ nationwide); however, regional trends and significant post-vaccination reductions in GE mortality (i.e., 69.9\% [63.1, 77.5] nationwide) were comparable to those observed in the younger age group (Fig. 3a).

The model showed significant decreases in mortality in children $<5$ years in the postversus pre-vaccination period at the national level (e.g., Poisson: $-72.4 \%[-73.5,-71.1]$ ) as well as by region (e.g., Costa $-65.6 \%$ [-69.6, 61.2], Sierra $-72.1 \%$ [- 74.0, - 70.0] and Oriente $-68.4 \%[-70.4,-66.3])$. Due to the small number of deaths in the Insular region (including no deaths post-vaccination), the models did not converge.

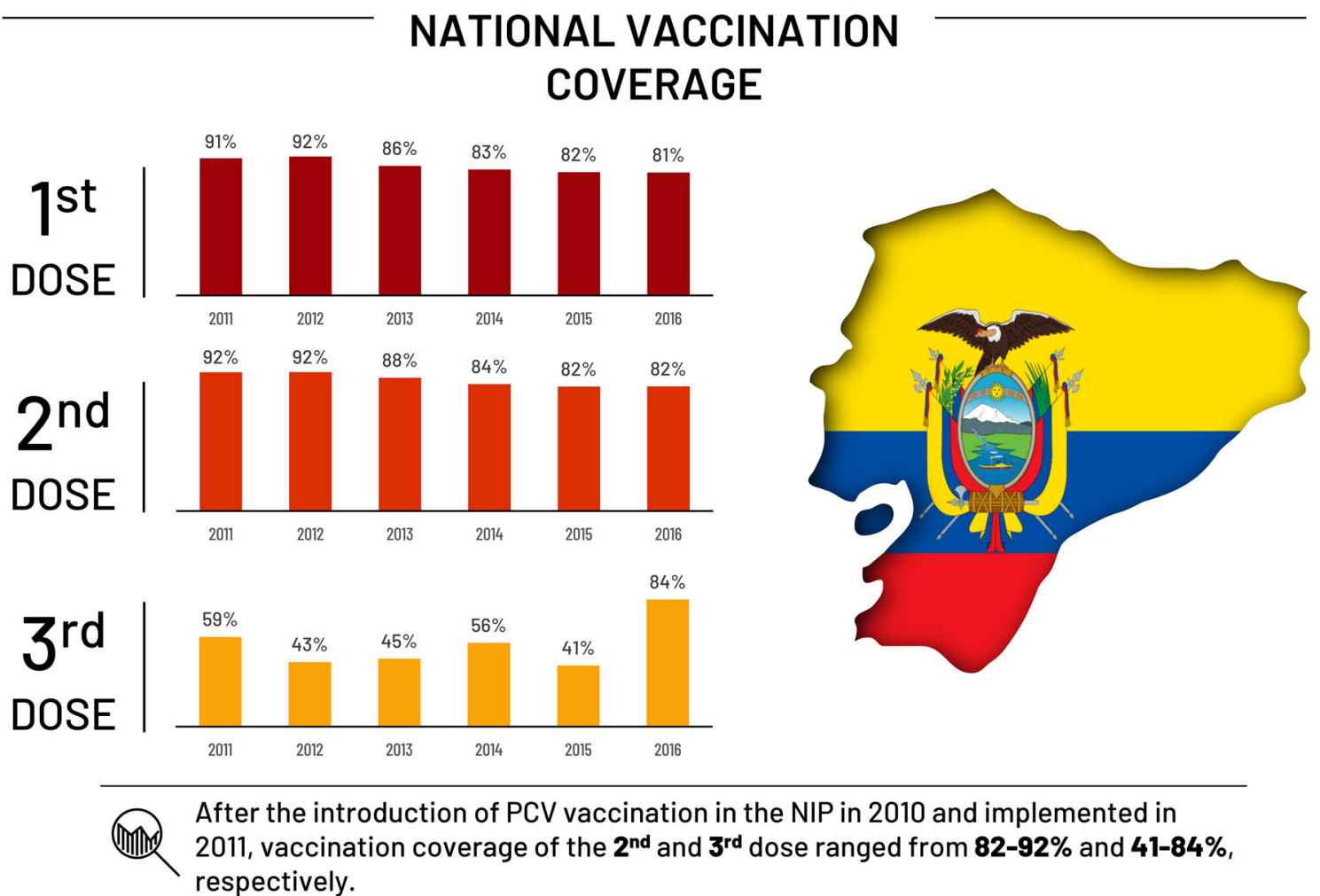

Fig. 4 PCV vaccine coverage data. No data were available by region or the year 2017. The population of infants $<1$ year old was used as the denominator. PCV $2+1$ schedule from 2011 to 2015 and then a $3+0$ schedule from 2016 onwards. NIP National Immunization Program, $P C V$ pneumococcal conjugate vaccine 


\section{(a) PNE MORTALITY}
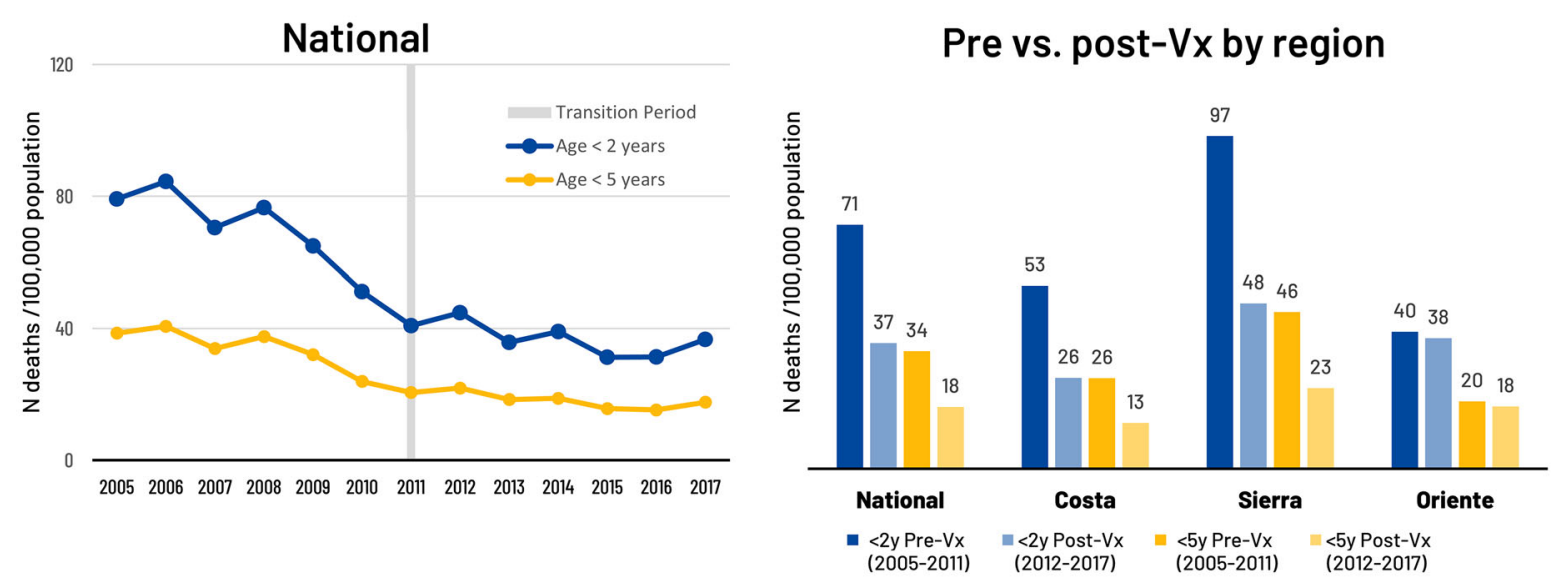

(b) PNE INCIDENCE

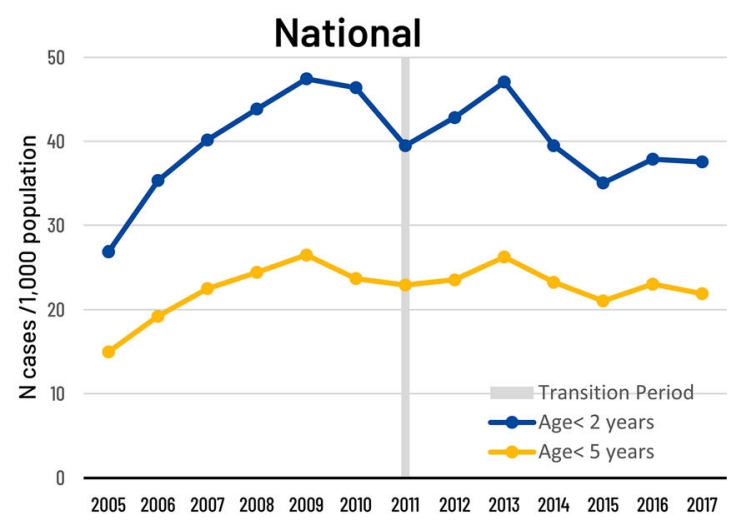

Fig. 5 National PNE a mortality $(/ 100,000)$ and $\mathbf{b}$ incidence (/1000) yearly trends (descriptive analysis). $N$ number, PNE pneumonia, $V x$ vaccination, $y$ years. Transition

\section{GE Incidence}

In children $<2$ years, 169,894 GE cases were reported over the study period (2005-2017), with the highest number of cases seen in the Costa region $(104,561)$ followed by Sierra $(51,313)$, Oriente $(13,467)$ and Insular $(220)$ regions. Incidences in the pre-vaccination period were 34.9/1000 (nationwide), highest in Costa (41.1) and lowest in Insular (25.0). Postvaccination, the national incidence decreased by $55.4 \%$ [ $95 \%$ CI $54.8,55.9]$, with significant decreases also seen in each region (Table 1 ,

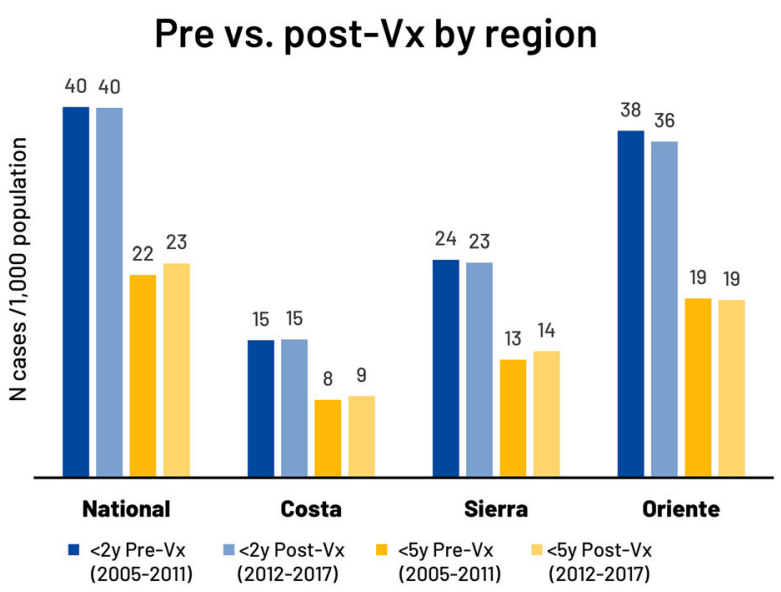

period: period during which the PCV vaccination was introduced in Ecuador. ICD-10 codes used were Pneumonia J12-J18

Supplementary Fig. 1a). Among all children $<5$ years, 249,509 GE cases were reported for 2005-2017 and pre-vaccination incidence was 19.1/1000 nationwide. Regional incidence trends and post-vaccination incidence reductions (i.e., 49.8\% [49.4, 50.2] nationwide) were similar to those in the younger age group (Fig. 3b).

For GE incidence, univariate analyses predicted significant decreases nationally (e.g., Poisson: - 51.2\% [- 53.5, - 48.9]) and by region (Costa $-44.8 \%$ [- 49.8, - 39.4], Sierra - 


\section{(a) IPD MORTALITY}
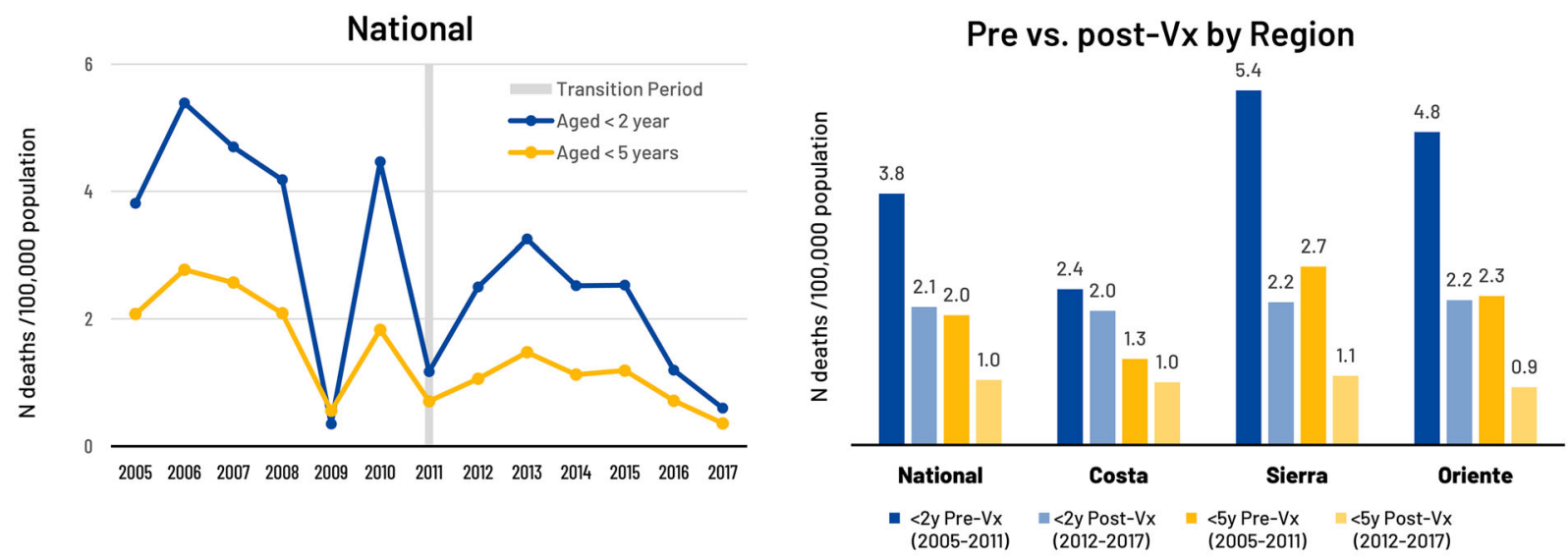

(b) IPD INCIDENCE

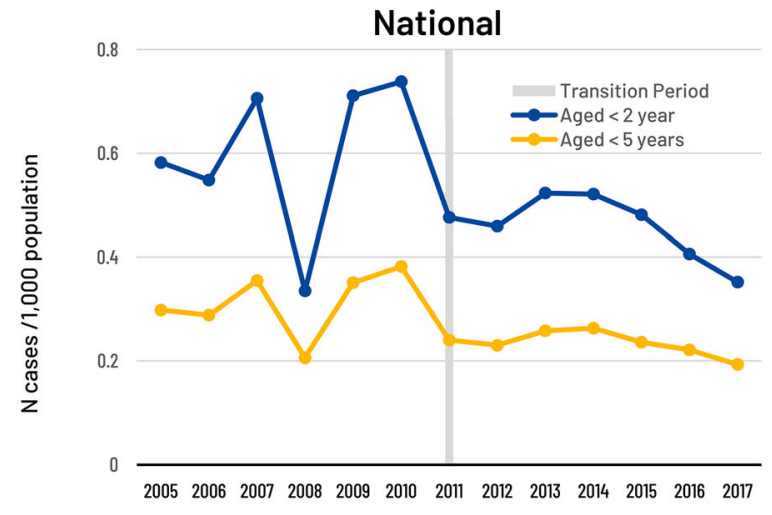

Fig. 6 National IPD a mortality $(/ 100,000)$ and $\mathbf{b}$ incidence $(/ 1000)$ yearly trends (descriptive analysis). IPD invasive pneumococcal disease, $N$ number, $V x$ vaccination,

$56.2 \%[-59.4,-52.7]$, Oriente $-49.6 \%$ [53.8, - 45.0] and Insular - 35.4\% [- 49.0, 18.3]). After adjusting for secular trends in multivariate analyses, there was a statistically significant reduction in the national incidence post-vaccination (e.g., Poisson: - 29.0\% [$35.2,-22.3]$ ), with significant reductions in some regions and non-significant increases in other regions.
Pre vs. post-Vx by Region

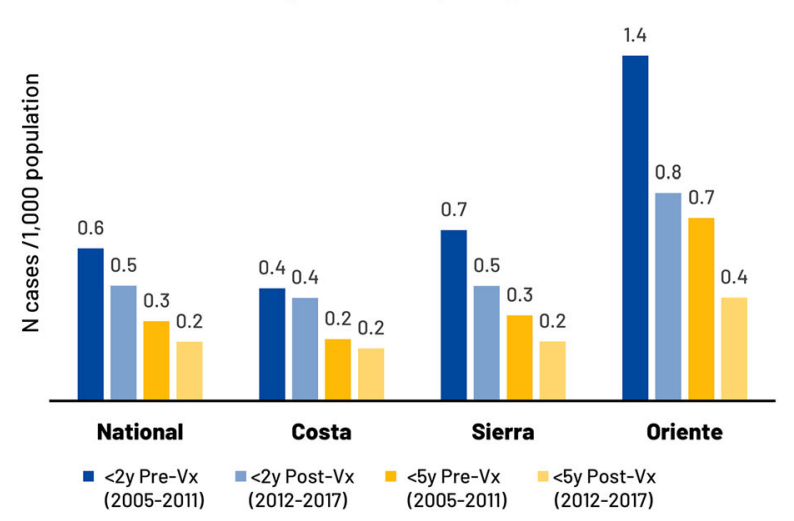

$y$ year. Transition period: period which pneumococcal conjugate vaccination was introduced in Ecuador. ICD-10 codes used for IPD were G00.1, A40.3, B95.3 and J13

\section{PCV Vaccination and Impact on PNE and IPD Mortality and Incidence}

\section{PCV Vaccine Coverage}

After PCV vaccination was recommended in the NIP in 2010 and implemented in 2011, national vaccination coverage of the second and third dose ranged from $82-92 \%$ and $41-84 \%$, respectively (Fig. 4). No vaccination coverage data were available by region or for the year 2017 . 


\section{PNE Mortality}

There were 4232 PNE deaths in children $<2$ years $(5196$ in children $<5$ years $)$ reported for 2005-2017. The regions with the highest numbers of deaths were Sierra (2479) and Costa (1530) followed by Oriente (215) and Insular (4). The national pre-vaccination mortality estimate was $70.84 / 100,000$ and was highest in Sierra (96.60) and lowest in Insular (36.17). Post-vaccination, there was a significant reduction in mortality of around 50\% nationwide and in the regions with the highest numbers of deaths (Table 1). Among children $<5$ years, the pre-vaccination mortality was $34.15 / 100,000$ with similar trends observed by region as in the younger age group. Overall, PNE mortality decreased by $47.4 \%$ (95\% CI 44.7 , 50.3) post-vaccination (Fig. 5a).

The Poisson model showed significant decreases in PNE mortality in children $<5$ years in the post- versus pre-vaccination period at the national level (e.g., Poisson: - 41.1\% [- 42.9, 39.3]) as well as in some regions (e.g., Poisson: Costa $-44.0 \%$ [- 48.1, - 39.5], Sierra - 49.7\% [- 51.7, - 47.6]). After adjusting for secular trends in the multivariate analysis, there was a statistically significant decrease in the postversus pre-vaccination period mortality at the national level (Poisson: - 7.7\% [- 13.8, - 1.2]) with non-significant decreases in the regions.

\section{PNE incidence}

Overall, 328,723 PNE cases were reported for 2005-2017 in children < 2 years; most cases were reported in Sierra $(82,780)$, followed by Costa $(60,830)$ and Oriente $(20,228)$, with few cases in the Insular (128) region. Prior to PCV vaccination, the national incidence was 40.09/ 1000 and varied significantly by region [i.e., highest in Oriente (37.50) and lowest in Insular (7.96) regions]. The PNE incidence remained relatively unchanged after vaccination, decreasing by $0.24 \%$ nationwide (Table 1 ). Among children $<5$ years, 468,027 PNE cases were reported for 2005-2017 with a national pre-vaccination incidence of 21.94/1000. Regional incidence trends were comparable to the younger age group. Overall, a 5.7\% reduction $[5.67,5.74]$ in PNE incidence was observed in this age group (Fig. 5b).
Univariate analyses (in children $<5$ years) showed a non-significant reduction nationally (e.g., Poisson: $-0.80 \%[-5.00,3.60]$ ) and in all regions in the post- versus pre-vaccination period, except in Costa where there was a significant increase in incidence $(16.0 \%$ [3.60, 29.8]). After adjusting for secular trends in multivariate analyses, there was a non-significant reduction in incidence post- versus pre- vaccination (e.g., Poisson: $-0.4 \%[-9.5,9.7])$ at the national and regional level, while Costa had a non-significant increase (e.g., Poisson: 11.4\% [- 13.0, 42.7]).

\section{IPD Mortality}

There were 227 IPD deaths in children $<2$ years (288 in children under 5 years) reported for 2005-2017, with most occurring in Sierra (125) and Costa (85) regions. Following PCV vaccination, the national mortality decreased from 3.83 to $2.11 / 100,000$ (45.0\% reduction [34.3, $59.1])$ with regional reductions of $59.7 \%$ and $13.9 \%$ in Sierra and Costa, respectively (Table 1, Supplementary Fig. 1b). Among children $<5$ years, the national mortality decreased post-vaccination by $50.0 \%$ (95\% CI 39.1, 63.9) from 1.98 to $0.99 / 100,000$, with similar regional trends as seen in children $<2$ years (Fig. 6a).

The Poisson model showed statistically significant decreases in IPD mortality in children $<5$ years in the post- versus prevaccination period at the national level ($51.1 \%$ [ $-57.2,-44.2])$ as well as in some regions (Costa $-47.3 \%$ [-61.0, - 28.9], Sierra $-48.7 \%$ [- 57.2, -38.5$]$ and Oriente $-57.9 \%$ $[-67.5,-45.6])$.

\section{IPD Incidence}

There were 4290 IPD cases in children $<2$ years reported for 2005-2017, with most cases in Sierra (1966) and Costa (1741), followed by Oriente (571) and Insular (10) regions. Before PCV vaccination, the national incidence was $0.61 / 1000$ and after PCV vaccination; it decreased significantly by $24.4 \%$ [23.0, 26.0] with regional variations (e.g., reduction of $32.8 \%$ in Sierra and $8.5 \%$ in Costa) (Table 1, Supplementary Fig. 1b). Among children $<5$ years, 5570 IPD cases were reported for 2005-2017. Incidence decreased from 0.32 to 
$0.23 / 1000$ (26.0\% reduction $[24.6,27.4]$, with similar trends by region as seen in children $<2$ years (Fig. $6 \mathrm{~b}$ ).

For IPD incidence (in children $<5$ years) univariate analyses showed a statistically significant reduction nationally (e.g., Poisson: $31.5 \%[-47.8,-10.1])$ and in Oriente $(-39.9 \%$ $[-60.3,-8.8])$ in the post- versus pre-vaccination period. After adjusting for secular trends in multivariate analyses, there was a non-significant reduction in incidence post- versus prevaccination (e.g., Poisson: - 25.8\% [- 59.4, 35.7]) at the national level and non-significant increasing or decreasing trends at the regional level.

\section{DISCUSSION}

With the WHO objective in mind of reducing childhood mortality through recommended universal infant vaccination programs, this study assessed the impact of RV and PCV vaccination on childhood mortality and incidence in Ecuador.

After RV vaccination began in 2007, coverage of the second dose was relatively high (79-97\%). In the post-RV vaccination period, GE incidence and mortality decreased significantly nationwide in children $<2$ years (by $55.4 \%$ [54.8, 55.9] and 70.7\% [63.1, 79.1], respectively). GE graphs showed a decreasing GE mortality and incidence trend before vaccination was introduced. GE incidence graphs showed decreases at the national and regional level suggesting a decline due to vaccination.

The impact of HRV vaccination on community RV prevalence, both symptomatic and asymptomatic, was assessed in rural Ecuador in a large population-based case-control study (from 2003 to 2013) and a smaller 2-year active surveillance study [16]. Post-vaccination, there was a significant decrease in all-cause diarrhea in both the case-control (69\%) and cohort study $(57 \%)$ in children $<1$ year. While most benefits were seen in the youngest (vaccinated) children, there was an indirect effect among older unvaccinated children; the overall prevalence of $\mathrm{RV}$ decreased by $56 \%$ in symptomatic cases and
$79 \%$ in asymptomatic cases among all children [16].

Latin American countries that implemented $\mathrm{RV}$ vaccination have demonstrated a positive impact on acute gastroenteritis (AGE) hospitalizations and mortality, in a meta-analysis of recent data up to 2018, with benefits seen in both low- and high-mortality countries [14]. In high-mortality countries (other than Ecuador), vaccine efficacy in children $<1$ year was $67 \%$ against RV hospitalization and $71 \%$ against severe RVGE among fully vaccinated children. In high-mortality countries in children $<1$ year, RV hospitalizations declined by $51 \%$ and AGE hospitalizations by $20 \%$ compared to the pre-vaccination period, while AGE mortality declined by $45 \%$. Based on 2015 coverage and hospitalization rates, vaccination was estimated to have prevented 37\% (95\% CI $27,47)$ of RV hospitalizations and 37\% (95\% CI 27,48 ) of $\mathrm{RV}$ deaths in children $<5$ years in high-mortality Latin American countries [14].

In Latin American countries, studies often must rely on passive surveillance data, which is useful for evaluating the population-level impact of RV vaccination and seasonal changes, but which also has limitations. For example, outcomes can be influenced by vaccine coverage levels or factors such as data gaps due to variable reporting over time, changes in case definitions and diagnostics, changes in access to healthcare or changes in health status or hygiene practices [30]. This study in six Latin American countries using sentinel RV surveillance networks found an overall $16 \%$ reduction in $\mathrm{RV}$-associated diarrhea hospitalizations with large country variations, a reduction in the seasonal peak and a shift in peak to later in the year in high-mortality countries. The lower reduction estimated versus other studies may be due to inclusion of any diarrhea case, regardless of severity [30]. Differences in case definitions and methods used across studies in the region result in variable estimates for the impact of vaccination; however, all studies have reported a positive impact of $\mathrm{RV}$ vaccination on prevalence of RV and hospitalizations [30] as found in our study.

After PCV vaccination was implemented in 2011, coverage of the second and third dose was 
$>80 \%$ and $40 \%$, respectively. The national incidence of pneumonia in children $<2$ years was $40.09 / 1000$ and remained stable (decrease of $0.24 \%$ post-vaccination), while the mortality was 70.84/100,000 and declined significantly by around 50\%. Graphs showed a decreasing pneumonia mortality trend prior to vaccine introduction, which continued in the postvaccination period. Pneumonia incidence trends appeared to increase for several years and had started to decline before vaccine introduction. Following vaccination, pneumonia incidence trends eventually appeared to stabilize, resulting in a small decrease in the post- versus pre-vaccination period. IPD national incidence $(0.61 / 1000)$ decreased significantly by $24.4 \%$ $[23.0,26.0]$ after PCV vaccination, while mortality decreased significantly by $45.0 \%$ [34.3, $59.1]$ (from 3.83 to $2.11 / 100,000$ ). Large yearly fluctuations in the pre-vaccination period as well as small numbers with IPD did not allow for adequate trend assessment.

In a time series analysis (2005-2015 national data) of PCV impact on pneumonia mortality and hospitalization in Ecuador [28], in the postvaccination period, there was a clear and significant reduction in pneumonia hospitalizations $\quad(27 \%$ and $33 \%$ for children $<1$ and $<5$ years, respectively); however, the reduction in pneumonia mortality was lower ( $14 \%$ and $10 \%$ for children $<1$ and $<5$ years, respectively) and with uncertainty, i.e., wide credible intervals. The authors reported that other studies assessing vaccine impact on pneumonia mortality also showed a decline but with similar difficulties related to uncertainty [28].

An analysis of all-cause pneumonia mortality data in children 2 months to 5 years old between 2000 and 2016 from ten Latin American and Caribbean countries was conducted using a range of time series model that controlled for other factors such as unrelated secular trends in mortality not affected by PCV as well as gaps in reporting. Mortality was found to decline in many countries following PCV vaccination, with the most important declines seen in Ecuador (25\% [95\% CI 4, 41]), Peru, Colombia, Mexico and Nicaragua. Data quality varied across countries, and most countries had low to moderate baseline pneumonia mortality, which could have affected estimates and levels of uncertainty around estimates (e.g., high uncertainty in Guyana, Honduras and Dominican Republic possibly due to low numbers of deaths reported). The overall results, however, support PCV vaccination as responsible for substantial declines in childhood mortality in this region [31].

In Brazil, 1 year after PHiD-CV introduction, there was a $23-29 \%$ reduction in pneumonia hospitalizations in young children in cities with high vaccine coverage [32]. In Peru, 3 years after PCV vaccination was introduced, there was a $35 \%$ reduction in mortality and $21 \%$ reduction in morbidity due to pneumonia in infants ( $<1$ year old) [33]. A recent analysis from 2000 to 2016 found a $25 \%$ decline in all-cause pneumonia mortality in children in Ecuador post-vaccination [31].

There were several limitations in our study due to the observational ecological design and use of passive surveillance data, which cannot control for external developments in the country that impact health outcomes (e.g., changes in healthcare access or poverty levels) or reporting quality (e.g., changing or incomplete data over time and by age group or region). Based on the distribution of data, neither Poisson nor other explored regression models provided an exact fit, yet the Poisson model generally fit better, and univariate analyses were in line with descriptive data findings. In multivariate analyses, however, results were sometimes non-significant because of interactions, e.g., at the regional level, the interaction between secular trend and age was significantly associated with GE mortality, which may have affected the association between vaccination period and mortality after adjustment. In addition, it was not possible to adjust for seasonal trends with the models. The Insular and Amazon regions are difficult to access, and the health care system in these regions is mostly primary care, which could have led to underreporting of cases. 


\section{CONCLUSION}

In conclusion, the impact of vaccination in Ecuador was assessed with post-vaccination data from 9 years of RV and 6 years of PCV programs. Significant decreases in GE and pneumococcal incidence and mortality have been observed in children $<5$ years of age and those with the highest burden, likely due to the important contribution of RV and PCV vaccination.

\section{ACKNOWLEDGEMENTS}

Funding. GlaxoSmithKline Biologicals SA funded this study (HO-17-19013) and covered all costs associated with the development and publication of this manuscript.

Medical writing, editorial, and other assistance. The authors thank Maria Mercedes Castrejon and Maria Gabriela Graña for the support in the conception of the study. The authors also thank the Business \& Decision Life Sciences platform for editorial assistance and manuscript coordination, on behalf of GSK. Maxime Bessières coordinated manuscript development and editorial support and Kavi Littlewood (Littlewood Writing Solutions, on behalf of GSK) provided writing support.

Authorship. All named authors meet the International Committee of Medical Journal Editors (ICMJE) criteria for authorship for this article, take responsibility for the integrity of the work as a whole, and have given their approval for this version to be published.

Author contributions. CT, CV and PJ were involved in the conception and/or the design of the study. CV, PJ and AGH participated in the data collection/generation of the study data. AGH, PJ, TR and VG were involved in the interpretation of the data. All authors reviewed and approved the final manuscript.

Disclosures. AGH, PJ and TR are employed by the GSK group of companies. PJ holds shares in the GSK group of companies. AGH, PJ and VP declare no other financial and non-financial relationships and activities. CV reports grants from JSS Medical Research LATAM during the conduct of the study. CT and VG declare no financial and non-financial relationships and activities and no conflicts of interest.

Compliance with ethics guidelines. This study used anonymized aggregated database data with no personally identifiable information which can be linked to a patient. It was therefore considered out of scope for ethics review based on Ministerial Agreement MSPCGDES-2018-0185-O from Ecuador's Ministry of Health (Coordinación General de Desarrollo Estratégico en Salud).

Data availability. The datasets generated during and/or analyzed during the current study are available from the corresponding author on reasonable request. The datasets were formally solicited from the main data sources outlined in Supplementary Table 1.

Trademark. Rotarix is a trademark owned by or licensed to the GSK group of companies. RotaTeq is a trademark owned by or licensed to Merck Sharp \& Dohme Corp. Synflorix is a trademark owned by or licensed to the GSK group of companies. Prevenar is a trademark owned by or licensed Wyeth LLC.

Open Access. This article is licensed under a Creative Commons Attribution-NonCommercial 4.0 International License, which permits any non-commercial use, sharing, adaptation, distribution and reproduction in any medium or format, as long as you give appropriate credit to the original author(s) and the source, provide a link to the Creative Commons licence, and indicate if changes were made. The images or other third party material in this article are included in the article's Creative Commons licence, unless indicated otherwise in a credit line to the material. If material is not included in the article's Creative Commons licence and your intended use is not permitted by statutory regulation or exceeds the permitted use, you will need to obtain permission directly from the copyright holder. To view a copy of this licence, 
visit http://creativecommons.org/licenses/bync/4.0/.

\section{REFERENCES}

1. Lanata CF, Fischer-Walker CL, Olascoaga AC, Torres CX, Aryee MJ, Black RE. Global causes of diarrheal disease mortality in children $<5$ years of age: a systematic review. PloS One. 2013;8(9):e72788.

2. Centers for Disease Control and Prevention (CDC). Morbidity and Mortality Weekly Report (MMWR): rotavirus surveillance, worldwide, 2001-2008. 2008. https://www.cdc.gov/mmwr/preview/ mmwrhtml/mm5746a3.htm. Accessed 21 Oct 2020

3. Tate JE, Burton AH, Boschi-Pinto C, Steele AD, Duque J, Parashar UD. 2008 estimate of worldwide rotavirus-associated mortality in children younger than 5 years before the introduction of universal rotavirus vaccination programmes: a systematic review and meta-analysis. Lancet Infect Dis. 2012;12(2):136-41.

4. Troeger C, Khalil IA, Rao PC, Cao S, Blacker BF, Ahmed $\mathrm{T}$, et al. Rotavirus vaccination and the global burden of rotavirus diarrhea among children younger than 5 years. JAMA Pediatr. 2018;172(10): 958-65.

5. Linhares AC, Stupka JA, Ciapponi A, Bardach AE, Glujovsky D, Aruj PK, et al. Burden and typing of rotavirus group A in Latin America and the Caribbean: systematic review and meta-analysis. Rev Med Virol. 2011;21(2):89-109.

6. Ministerio de Salud Pública. Ecuador 2007-Indicadores Basicos de Salud. 2007. http://www.uasb. edu.ec/UserFiles/372/File/pdfs/COMISION\% 20ANDINA\%20DE\%20LA\%20SALUD/Perfil\% 20salud\%20Ecuador.pdf. Accessed 21 Oct 2020

7. Ruiz-Palacios GM, Pérez-Schael I, Velázquez FR, Abate H, Breuer T, Clemens SC, et al. Safety and efficacy of an attenuated vaccine against severe rotavirus gastroenteritis. N Engl J Med. 2006;354(1): $11-22$.

8. Food and Drug Administration (FDA). FDA Rotarix-full prescribing information. 2008. https://www.fda.gov/media/75726/download. Accessed 21 Oct 2020

9. Vesikari T, Matson DO, Dennehy P, Van Damme P, Santosham M, Rodriguez Z, et al. Safety and efficacy of a pentavalent human-bovine (WC3) reassortant rotavirus vaccine. N Engl J Med. 2006;354(1):23-33.
10. Food and Drug Adminisistration (FDA). FDA Rotateq-full prescribing information. 2006. https:// www.fda.gov/media/75718/download. Accessed 21 Oct 2020

11. Centers for Disease Control and Prevention (CDC). Morbidity and Mortality Weekly Report (MMWR): progress in the introduction of rotavirus vaccineLatin America and the Caribbean, 2006-2010. 2011. https://www.cdc.gov/mmwr/pdf/wk/mm6047.pdf. Accessed 21 Oct 2020

12. Paternina-Caicedo A, Parashar UD, Alvis-Guzmán N, De Oliveira LH, Castaño-Zuluaga A, Cotes-Cantillo $\mathrm{K}$, et al. Effect of rotavirus vaccine on childhood diarrhea mortality in five Latin American countries. Vaccine. 2015;33(32):3923-8.

13. Ministerio de Salud Pública. Estrategia Nacional de Inmunizaciones, ENI: Programa Ampliado de Inmunizaciones (PAI) 2015. 2015. https://www. salud.gob.ec/programa-ampliado-deinmunizaciones-pai./. Accessed 21 Oct 2020

14. Chavers T, De Oliveira LH, Parashar UD, Tate JE. Post-licensure experience with rotavirus vaccination in Latin America and the Caribbean: a systematic review and meta-analysis. Expert Rev Vaccines. 2018;17(11):1037-51.

15. Santos VS, Marques DP, Martins-Filho PR, Cuevas LE, Gurgel RQ. Effectiveness of rotavirus vaccines against rotavirus infection and hospitalization in Latin America: systematic review and meta-analysis. Infect Dis Poverty. 2016;5(1):83.

16. Kraay ANM, Ionides EL, Lee GO, Trujillo WFC, Eisenberg JNS. Effect of childhood rotavirus vaccination on community rotavirus prevalence in rural Ecuador, 2008-13. Int J Epidemiol. 2020;49(5): 1691-701.

17. O'Brien KL, Wolfson LJ, Watt JP, Henkle E, DeloriaKnoll M, McCall N, et al. Burden of disease caused by Streptococcus pneumoniae in children younger than 5 years: global estimates. Lancet (London, England). 2009;374(9693):893-902.

18. Valenzuela MT, O’Loughlin R, De La Hoz F, Gomez E, Constenla D, Sinha A, et al. The burden of pneumococcal disease among Latin American and Caribbean children: review of the evidence. Revista panamericana de salud publica Pan Am J Public Health. 2009;25(3):270-9.

19. Sinha A, Constenla D, Valencia JE, O'Loughlin R, Gomez E, de la Hoz F, et al. Cost-effectiveness of pneumococcal conjugate vaccination in Latin America and the Caribbean: a regional analysis. Revista panamericana de salud publica Pan Am J Public Health. 2008;24(5):304-13. 
20. de Oliveira LH, Trumbo SP, Ruiz Matus C, Sanwogou NJ, Toscano CM. Pneumococcal conjugate vaccine introduction in Latin America and the Caribbean: progress and lessons learned. Expert Rev Vaccines. 2016;15(10):1295-304.

21. Pittet LF, Posfay-Barbe KM. Pneumococcal vaccines for children: a global public health priority. Clin Microbiol Infect. 2012;18(Suppl 5):25-36.

22. World Health Organization (WHO). Pneumococcal conjugate vaccines in infants and children under 5 years of age: WHO position paper-February 2019. 2019. https://apps.who.int/iris/bitstream/handle/ 10665/310968/WER9408.pdf?ua=1. Accessed 23 Oct 2020

23. World Health Organization (WHO). SynflorixWHO Package Insert. 2011. https://www.who.int/ immunization_standards/vaccine_quality/ Synflorix_WHO_leaflet_EN_May_2011.pdf. Accessed 21 Oct 2020

24. Balsells E, Guillot L, Nair H, Kyaw MH. Serotype distribution of Streptococcus pneumoniae causing invasive disease in children in the post-PCV era: a systematic review and meta-analysis. PLoS ONE. 2017;12(5): e0177113.

25. Azzari C, Martinón-Torres F, Schmitt HJ, Dagan R. Evolving role of 13-valent pneumococcal conjugate vaccine in clinical practice. Pediatr Infect Dis J. 2014;33(8):858-64.

26. World Health Organization (WHO). Pneumococcal vaccines: WHO position paper-2012. 2012. https://www.who.int/wer/2012/wer8714.pdf?ua=1. Accessed 23 Oct 2020

27. de Oliveira LH, Toscano CM, Sanwogou NJ, RuizMatus C, Tambini G, Roses-Periago M, et al. Systematic documentation of new vaccine introduction in selected countries of the Latin American Region. Vaccine. 2013;31(Suppl 3):C114-22.
28. Jimbo Sotomayor R, Toscano CM, Sánchez Choez X, Vilema Ortíz M, Rivas Condo J, Ghisays G, et al. Impact of pneumococcal conjugate vaccine on pneumonia hospitalization and mortality in children and elderly in Ecuador: time series analyses. Vaccine. 2020;38(45):7033-9.

29. Hildebrandt M, Bender R, Gehrmann U, Blettner M. Calculating confidence intervals for impact numbers. BMC Med Res Methodol. 2006;6:32.

30. Shioda K, de Oliveira LH, Sanwogou J, Rey-Benito G, Nuñez Azzad D, Castillo RE, et al. Identifying signatures of the impact of rotavirus vaccines on hospitalizations using sentinel surveillance data from Latin American countries. Vaccine. 2020;38(2):323-9.

31. de Oliveira LH, Shioda K, Valenzuela MT, Janusz $\mathrm{CB}$, Rearte A, Sbarra AN, et al. Declines in pneumonia mortality following the introduction of pneumococcal conjugate vaccines in Latin American and Caribbean countries. Clin Infect Dis. 2021;73(2):306-13.

32. Afonso ET, Minamisava R, Bierrenbach AL, Escalante JJ, Alencar AP, Domingues CM, et al. Effect of 10 -valent pneumococcal vaccine on pneumonia among children. Braz Emerg Infect Dis. 2013;19(4): 589-97.

33. Suarez V, Michel F, Toscano CM, Bierrenbach AL, Gonzales M, Alencar AP, et al. Impact of pneumococcal conjugate vaccine in children morbidity and mortality in Peru: time series analyses. Vaccine. 2016;34(39):4738-43.

\section{Publisher's Note}

Springer Nature remains neutral with regard to jurisdictional claims in published maps and institutional affiliations. 